\title{
The Relationship Between Self-Regulated Learning and Academic Achievement for a Sample of Community College Students at King Saud University
}

\author{
Khaled Alotaibi ${ }^{1}$, Riyad Tohmaz ${ }^{2}$, Omar Jabak $^{3, *}$ \\ ${ }^{1}$ Department of Educational Psychology, King Saud University, Riyadh, Saudi Arabia \\ ${ }^{2}$ Department of Administrative Sciences, Community College at King Saud University, Riyadh, Saudi Arabia \\ ${ }^{3}$ Department of Arts and Education, Community College at King Saud University, Riyadh, Saudi Arabia
}

Email address:

kragges@ksu.edu.sa (K. Alotaibi),ojabak@ksu.edu.sa (O. Jabak)

${ }^{*}$ Corresponding author

\section{To cite this article:}

Khaled Alotaibi, Riyad Tohmaz, Omar Jabak. The Relationship Between Self-Regulated Learning and Academic Achievement for a Sample of Community College Students at King Saud University. Education Journal. Vol. 6, No. 1, 2017, pp. 28-37.

doi: $10.11648 /$ j.edu.20170601.14

Received: December 22, 2016; Accepted: January 3, 2017; Published: January 23, 2017

\begin{abstract}
Due to the paucity of self-regulated learning studies at higher education level in Saudi Arabia, the present study examined the relationshipbetween self-regulated learning and academic achievement of Community College students at King Saud University. The sample of the study was comprised of 356 students attending a preparatory year program. The study used an SRL instrument developed by Purdie et al. (1996) and validated by Ahmad (2007) for the Arab learning context, and academic achievement was measured by students' scores in the areas of English language skills and mathematics. Results indicatedthat the study instrument was valid and reliable for use in a Saudi university environment. Furthermore, results indicated that there is a significant and positive relationshipbetween self-regulated learningand the academic achievement of students. Similarly, the constructs of SRL (i.e., goal setting and planning, keeping records and monitoring, rehearsal and memorization, and seeking social assistance), especially goal setting and planning, were found to be significantly and positively related to achievement. Additionally, SRL and its constructs, especially goal setting and planning, were found to be significant predictors of academic achievement. The implications and suggestions forfuture research are discussed.
\end{abstract}

Keywords: Self-Regulated Learning, Academic Achievement, Higher Education, Saudi University

\section{Introduction}

Human knowledge is cumulative and participatory in nature. It doubles every five years in an era characterized by enormous revolution of information, which has in turn produced a strong tendency towards giving more and more attention to developing students' integrated learning processes. So, the goal of the educational process is no longerlimited to providing students with knowledge and facts, but extends to developing their thinking and analytical abilities, and providingthem with higher mental skills to deal with the emerging information and knowledge efficiently and effectively. According to the Organization for Economic Cooperation and Development (OECD) report (2003), the world is moving towards knowledge-based economies, and this imposes new requirements and demandsupon the education systems to expand and enhance learners' knowledge, skills, and attitudes. Hence, it is necessary to think deeply about education systems;many learning theories provide interpretations, applications, and models to createstudentswho are able to meet the challenges of this era. Amongthe most important models that have emerged in this field is the "Self-Regulated Learning" (SRL) model. This new curve of learning, which has become one of the most important topics and interests in education, focuses attention on how to empowerstudents to performlearning practices by themselves. Because SRL depends heavily on students' proactive roles in their learning outcomes, it has been one of the most widely debated topics in the field of academic 
learning (Dent and Koenka, 2015).

According to Zimmerman (2002), SRL is a self-directive process that enables students to transform their mental abilities into academic skills, and it is a regular and mental knowledge process in which learners engage very actively until their learning objectives are realized. Pintrich (2000:453) defines SRL as "an active, constructive process whereby learners set goals for their learning and then attempt to monitor, regulate, and control their cognition, motivation and behavior, guided and constrained by their goals and the contextual features in the environment".

Broadly speaking, SRL studentshave purposeful and strategic behaviors and learn with a high degree of perseverance; they think about their thinking (metacognition), plan, monitor, and evaluate their personal progress against a standard, and have an internal motivation to learn (Zimmerman, 1995). They also have a high degree of self-efficacy, and control their learning environment to stimulate learning to the greatest level possible. Accordingly, students who claim responsibility for their learning and results have a high probability of increasing their capacity to evoke learning experiences stored in their memory, develop their sense of responsibility, and gain independent learning skills. In this case, academic achievements and selfconfidence will be raised, and learning goals will be met.

In recent years, the concept of SRL has become the focus of applied educational studies as an important variable in boosting academic achievement and bringing about success (Tanriseven and Dilmac, 2013). Although Western academia has paid great attention to measuring the cognitive, motivational, and behavioral constructs of SRL and their impact on academic achievement, surprisingly, the Arab research environmentstill lacks such attentionto this valuable phenomenon and its role in learning success. Due to the limited number of research in the Arab learning context, especially in Saudi Arabia, the present study tries to explore the relationshipthat SRL has withacademic achievement.

\section{Literature Review}

\subsection{SRL Concept, Theories and Models}

Behavioural theories in self-regulated learning (SRL) in education have a backdropof not considering the learners' internal states (e.g. emotions, motivations, thoughts, and beliefs), instead concentrating heavily on learners' selfcontrol mechanisms (e.g. self-mentoring, self-reinforcement, self-evaluation, self-correction, and self-instruction) (Mace et al., 2001). Similarly, cognitive theories focused on students'cognitive skills and abilities that fully account for their learning, also offer an incomplete explanation of students' learning processes. Against these backdrops, cognitive SRL theories and models have emerged to take into accountthese backdrops by focusing on learners'proactive roles in developing their own skills and strategies, and how theycontrol their learning processes and environment (Schunk and Zimmerman, 2008). Three of these theories have been used extensively in learning contexts. These theories are: information processing, social constructivist, and social cognitive theories.

Information processing theory addresses how students process information they receive using a set of cognitive functions such as searching, perceiving, monitoring, rehearsing and transformation of information. Defining the learning task clearly, setting goals and implementing planned learning strategies for attaining the desired learning situation, and conducting self-evaluation to assess success are the main phases of information processing models (Schunk, 2005). In contrast, social constructivist theory stresses social interaction over observation. According to Vygotsky's theory of social learning (1978), social context (e.g. interaction with others, language, and culture) plays a crucialrole in formulating students' cognitive functions, and must be explained as the product of social interactions. Vygotsky (1978) argued that every cognitive function appears gradually in the learning process at two levels: interpsychological level (regulated by others-social interaction) and intrapsychological level (regulated by the learner him or herself). Continuous interaction between these two levels and the environment was proposed in Bandura's (1986) social cognitive theory. Personal processes, behaviours, and environment interact reciprocally to influence students' functioning and determine any changes needed to modify their cognition, perceptions, strategies, emotions and behaviours. This reciprocal causation model, as referred by Bandura (1986), is the one most well fitted to SRL because of the dynamic nature of its triadic elements during the learning process, as these elements must be subject to self-monitoring for the purpose of adjustingstudents' cognition, strategies, affects and behaviours.

It is found that SRL models have four shared assumptions. These assumptions are (Pintrich, 2004): (a) learners have active roles in determining their learning goals and strategies; (b) learners have the ability to regulate the SRL components such as monitoring, behavior, environment, self-efficacy, self-evaluative judgments, motivation and control of cognition; (c) learners evaluate their learning progress against preset goals, criteria and standards; (d) SRL is not just determined by individual qualities or attributes and the environment but also students' cognition, motivation and behavior.

Therefore, the core of the SRL concept depends on the student's ability to be independent in pursing their educational and life goals (Perry et al., 2006). In contrast to traditional learning processes, SRL focuses on how students can activate, modify, and maintain their learning practices based on a set of self-related processes (Schunk and Zimmerman, 2008). Butler and Winne (1995) argued that SRL students cyclically use a deliberate, judgmental, and adaptive process to adjust their strategies for approaching learning tasks. This process depends on students' motivation to engage in learning tasks, promoted by their physical and social environment (Butler, 2002). In addition, SRL as a 
system can foster students' higher thinking skills in solving problems, and enable them to deal with and interact effectively with their surrounding environment by applying their natural qualities and abilities (Corsi, 2010).

In the light of social cognitive theory, SRL can be described as a complicated process entailing cognitive, motivational, and contextual components such as goal setting, observation, judgment and reaction at a selfperceptible level.

\subsection{SRL and Academic Achievement}

Recently, there has been increasing interest among researchers in the field of educational psychology in how students can improve their academic achievements through regulation of their learning processes and strategies. Some empirical studies show that SRL is an essential stimulus to academic achievement (e.g. Zimmerman, 2008; Farajollahi and Moenikia, 2010; Rakes and Dunn, 2010; Zimmerman and Schunk, 2011; Beishuizen and Steffens, 2011; Effeney et al., 2013; Rosário et al., 2013; Fadlelmulaet al., 2015). In this respect, it can be argued that the concept of SRLmarks a shift in educational research fromconsidering students' learning capabilities and environments as fixed entities, to focusing on students' learning processes and responses, which are dynamic in nature, and influence their academic success.

Schunk (2005) argued that students' skills and abilities alone do not account for differences in their academic achievement, and that other factors such as self-regulation should be taken into consideration. The basic assumption behind this argument is the fact that effective self-regulated learners have a high degree of internal motivation; because of this, they have a greater readiness to exert the needed efforts and perseverefor long periods of time than those who do not have self-regulation. They alsoapplying their learning experiences efficiently and in different ways, and have a large inventory of cognitive and meta-cognitive strategies. In addition, they have the ability to arrange and organize themselves in a timely manner, and to identify their learning goals and persevere to reach them. Self-monitoring also enables themto control their progress toward the achievement of their learning goals, and make the required adjustments to their future learning activities and processes (Bembenutty, 2006). By the same token, Hong et al. (2009) believed that various learning interventions and sources such as experimental studies and formal observations can encourage students to capitalize on SRL, which is found to have a significant impact on their academic achievement. Recently, Fabriz, Dignath-van Ewijk, Poarch, and Büttner (2014) concluded that "SRL is an important key competence for university students... and students should be informed on the benefits of SRL to increase their motivation" (p. 239).

The majority of researchers in the field of SRL focus their attention on investigating the relationship between SRL and academic achievement in primary and secondary school contexts (e.g. Zimmerman and Martinez-Pons, 1986; Pintrich and DeGroot, 1990; Hassan, 1995; Ibrahim, 1996; Sui-Chu, 2004; Judd, 2005; Hong et al., 2009; Acar and Aktamis, 2010;
Ahmad et al., 2012; Ocak and Yamac, 2013; Sadia and Uyar, 2013; Fadlelmula et al., 2015), while a limited number of researchers were found to have investigated this relationship among university or college students, especially in Arab environments such as Saudi Arabia. However, previous studies showed a significant relationship between SRL and academic performance either in terms of GPA scores or certain subject scores. For example, Chen's (2002) study, with a sample of 197 undergraduates at Midwestern University in the USA, revealed that meta-cognitive SRL was one of the most important predictors of college students' academic performance in an "introduction to information systems" course. In Egypt, Ahmad (2007) conducted his study on a sample of 128 students from the faculty of education. The results of this study revealed positive relationships between SRL strategies and students' academic achievement.

Experimentally, Bail et al. (2008) conducted a study to explore the impact of SRL skills on students' academic achievement in certain courses at the University of Hawaii. The 79 students forming the experimental group were subjected to SRL skills development training program, while the 78 constituting the control groupwere not subjected to this program. The findings of the study showed that the students of the experimental group who developed theirSRL skillsdemonstratedbetter academic achievement than thosestudents in the control group. Similarly, Perels et al. (2009) concluded that it is possible to support self-regulation competencies and mathematical achievement by selfregulation intervention within regular mathematics lessons.

For Jordan's learning context, Al-Jarrah's (2010) study examined the predictability of SRL components of academic achievement, and whether academic achievement differs among students with high/ low levels of SRL. Purdie et al.'s (1996) SRL scale was used on a sample of 331 male and female undergraduate students from Yarmouk University. The results of his study revealed that there were statistically significant differences in academic achievement between students with high/ low scores on the SRL components of goal setting and planning, rehearsing and memorizing in the favor of the students with high level SRL, and that keeping records and monitoring, and goal setting and planning components predict academic achievement among students. In another study from a United Arab Emirates setting, AlKhatib (2010) found that SRL is a significant predicator of college students' academic performance $(n=404)$.

Furthermore, DiBenedetto and Bembenutty's(2011) study provided support for the expected association between SRL and science achievement in courses deemed necessary for a major in science among urban college students in New York $(n=57)$. In the same vein, Peng (2012) conducted a study to investigate the relationship between SRL and academic achievement. A sample of 101 college students from Jilin Normal University in Chine participated in the study; 54\% were males. Findings showed that self-regulation, cognitive strategies, and anxiety were important predictors of academic achievement in science. His study indicated that SRL improves students' self-satisfaction and their motivation, and therefore 
enhances their academic achievement. Recently, Muhammad and Abu Bakar (2015) examined the relationship between SRL and academic achievement among UniSZA undergraduate students in Malaysia. A sample of 364 students from nine colleges was selected randomly. Results showed that there is a strong relationship between SRL and academic achievement, and SRL serves as a good predictor of higher academic performance (GPA). This result was consistent with Yusuf's (2011) study which was carried out on a sample of 300 university students in Malaysia, and revealed direct and indirect influences of SRL on academic achievement.

A thoroughly review of literaturein the Saudi learning context indicates that there is only one piece ofresearch-to the best of this researcher's knowledge- examining the relationship between SRL and academic performance among university students. This study was conducted by Ismail and Sharma (2012) to investigate the relationship between SRL strategies and academic achievement among 236 undergraduates across different academic levels majoring in English at a Saudi Arabian University. Based on the eleven SRL strategies adopted from Pintrich's et al. (1993) findings, the study revealed that there is a positive relationship between SRL strategiesand academic performance (in term of student's GPA), and these strategies can explain a significant amount of variation in the students' GPA. Due to the paucity of research in such an important field in the Saudi learning context, the present study tries to examine the psychometric properties of the Arabic version of SRL Purdie et al. (1996) scale in Saudi higher education setting, and the association between SRL and the academic achievement of Saudi university students. Although the positive impact of SRL on academic achievement has been well recognized in the above- mentioned studies, it is necessary to investigate its impact in the Saudi learning context to enable Saudi university students to enhance their academic success. According to the Saudi National Centre for assessment in Higher Education, the majority of Saudi students have clear weaknesses in their English languageand mathematics skills in the light of the General Aptitude Test results. Therefore, this study tries to explore therole that SRL may play in enhancing Saudi universitystudents' levels of achievement in these two subjects by testing the following hypotheses:

$\mathrm{H}_{1}$ : There will be a significant relationship between SRL and academic achievement of Saudi university students as measured by their scores in the area of English language skills and mathematics.

$\mathrm{H}_{2}$ : SRL will significantly predict academic achievement of Saudi university students in English language skills and mathematics.

\section{Method}

\subsection{Participants}

The participants in this study were 356 community college (CC) students at King Saudi University (KSU) in Riyadh. $\mathrm{KSU}$ is the oldest and largest university in Saudi Arabia under the control of the Ministry of Education. All participants were males and their age range was 18-20 years old with a mean of 19.43 ( $\mathrm{SD}=0.874)$. They were enrolled in first and second Preparatory Year (PY) courses including English language skills and mathematics. After completing the requirements of PY courses, students are distributed to community college programs (computer science and administrative science) according to their GPAs. Therefore, the sample for this study is a homogeneous one in term of participants' demographic characteristics, cultural background, and instructional inputs. Students voluntarily participated in this study.

\subsection{Data Collecting Instrument}

The self-report instrument developed by Purdie et al. (1996), and validated for Arab setting by Ahmad (2007) was used to assess the level of students in SRL components. This instrument was applied in Purdie et al.'s (1996) study on a sample of 254 secondary students, and itis comprised of 28 items distributed equally among four SRL constructs. These constructs are:

A- Goal setting and planning: refers to students' ability to set general and specific learning goals for short and long term periods, develop action plans in a specific timetable, and complete related activities to achieve their learning goals (e.g. I prepare a timetable for studying each subject).

B- Keeping records and monitoring: refers to students' abilityto monitor their learning activities and the tasks which are carried out to achieve their learning goals, and record them in evaluative manner in order to remain on track (e.g. I write notes during discussion that took place in the lecture).

C- Rehearsal and memorization: refers to the ability of a student to memorize material through reading it aloud or silently (e.g. I repeat difficult words several times until I can memorize them).

D- Seeking social assistance: refers to students resortingto one of their family members, teachers or classmates to help themto understand the learning material or do thehomework (e.g. I ask my colleagues to help me in solving difficult problems).

The instrument's items were rated on 5-point Likert scale from 1"strongly disagree" to 5 "strongly agree". To validate Purdie's et al. (1996) instrument in the Arab context, Ahmad (2007) employed this instrument on (160) undergraduate students, after translating it into the Arabic language. According to the opinions of five professorsspecializing in educational psychology, the instrument showed a high degree of content validity. In addition, the 28 items of this instrument were subjected toa principal components analysis with Varimax rotation method. Ahmad's (2007) study analysis revealed the presence of four constructs with Eigenvalues exceeding one, and these constructs explained $51.48 \%$ of the total variance. Furthermore, the correlation matrix showed significant correlations between items and their related constructs. All constructs also showed good internal reliability with Cronbach's alpha value above 0.80. In a similar approach, Al-jarrah (2010) found that this Arabic version of the instrument was characterized by high content validity and reliability (Cronbach's alpha between.61 and.75)in an Arabuniversity context $(\mathrm{N}=60)$. Recently, Helat and Kojah (2015) applied this 
instrument in the context of Jordanian university students $(\mathrm{N}=110)$, and found that the Arabic version of Purdie et al.'s(1996) instrument had a high temporal stability with a testretest correlation of 0.75 .

For the present study, Purdie et al.'s (1996) self-report instrument as prepared by Ahmad (2007) was subjected to review byseven professors specializing in educational psychology at KSU. All content validity ratios were above 0.60 , and all content validity indexes were above 0.85 . Therefore, all items were approved. All selected professors were agreed on the clarity and simplicity of the instrument. In addition, a pilot test with 35 students from outside the original study sample was conducted to ensuretest-retest reliability and internal consistency in a Saudi context. These students answered the scale in twotime frames, separated by five weeks. Results showed that values of Cronbach's alpha coefficient $(\alpha)$ were satisfactory for the full instrument items $(\alpha=0.88)$, and for each instrument construct $(\alpha$ Goal setting and planning $=0.82 ; \alpha$ Keeping records and monitoring $=0.86 ; \alpha$ Rehearsal and memorization $=0.85 ; \alpha$ Seeking social assistance $=0.81$ ). Furthermore, the correlation between the twotime frames for the full instrument was significant with a value of $\left(r_{t t}=0.81\right)$. Therefore, this instrument has good psychometric properties in term of content validity and reliability.

\subsection{Study Procedures}

Permission was obtained from Ahmad (2007), the developer of the Arabic SRL test instrument, and from the Dean of CC in KSU.400 participants were invited to voluntarily participate in this study. Informed consent was signedby all participants, and they were informed that their responses would be confidential. The instrument in the form of a questionnaire was distributed to the participantsin twotime frames, separated by five weeks, at the beginning of the first semester of the 2015/2016 academic year. With the assistance of PY supervisors, all questionnaires were distributed during participants' regular English language skills and mathematics classrooms. No time limit was imposed for the completion of the instrument. Out of the 400 instruments distributed, 356 completed questionnaires were obtained (response rate $=89 \%$ ). At the end of the PY, the participants' academic achievement levels in English language skills and mathematics were measured by the total scores from 100 points they obtained at the end of each course.

\section{Results}

\subsection{Principal Component Analysis (PCA) and Confirmatory Factor Analysis (CFA)}

To determine the underlying constructs of the study instrument, PCA and Varimax rotation method was used. The results of PCA presented in Table 1 show that four interpretable factors with loading exceeding 0.40 and Eigenvalues exceeding 1 were identified. Similar to previous studies (Purdie et al., 1996; Ahmad, 2007), all items are loaded uniquely on their related construct. These four factors were retained with $71.6 \%$ of the total variance.

Table 1. Principal Component Analysis (PCA) Results.

\begin{tabular}{|c|c|c|c|c|c|}
\hline Items No. & $\begin{array}{l}\text { 1st factor: } \\
\text { SRL }\end{array}$ & $\begin{array}{l}\text { Factor 1: Goal setting } \\
\text { and planning }\end{array}$ & $\begin{array}{l}\text { Factor 2:Keeping Records } \\
\text { and Monitoring }\end{array}$ & $\begin{array}{l}\text { Factor 3:Rehearsal } \\
\text { and Memorization }\end{array}$ & $\begin{array}{l}\text { Factor 4:Seeking } \\
\text { Social Assistance }\end{array}$ \\
\hline 1 & 0.73 & 0.67 & & & \\
\hline 2 & 0.67 & 0.63 & & & \\
\hline 3 & 0.77 & 0.81 & & & \\
\hline 4 & 0.89 & 0.84 & & & \\
\hline 5 & 0.69 & 0.82 & & & \\
\hline 6 & 0.81 & 0.75 & & & \\
\hline 7 & 0.78 & 0.69 & & & \\
\hline 8 & 0.78 & & 0.66 & & \\
\hline 9 & 0.58 & & 0.78 & & \\
\hline 10 & 0.88 & & 0.88 & & \\
\hline 11 & 0.64 & & 0.77 & & \\
\hline 12 & 0.79 & & 0.77 & & \\
\hline 13 & 0.82 & & 0.83 & & \\
\hline 14 & 0.86 & & 0.79 & & \\
\hline 15 & 0.73 & & & 0.67 & \\
\hline 16 & 0.76 & & & 0.75 & \\
\hline 17 & 0.83 & & & 0.81 & \\
\hline 18 & 0.66 & & & 0.79 & \\
\hline 19 & 0.75 & & & 0.57 & \\
\hline 20 & 0.62 & & & 0.88 & \\
\hline 21 & 0.57 & & & 0.69 & \\
\hline 22 & 0.79 & & & & 0.63 \\
\hline 23 & 0.60 & & & & 0.85 \\
\hline 24 & 0.69 & & & & 0.81 \\
\hline 25 & 0.71 & & & & 0.77 \\
\hline 26 & 0.82 & & & & 0.73 \\
\hline 27 & 0.66 & & & & 0.63 \\
\hline 28 & 0.79 & & & & 0.78 \\
\hline Percentage of variance explained & $71.6 \%$ & $21.1 \%$ & $15.8 \%$ & $18.3 \%$ & $16.4 \%$ \\
\hline
\end{tabular}

Sampling Adequacy $(\mathrm{KMO})=0.93$ 
To examine the four-construct applicability of the SRL instrument used in the present study, a one-factor model, two-factor model, three-factor model, and four-factor model for its items were analyzed with CFA. Table 2 shows the results of CFA for the present study.

Table 2. Confirmatory Factor Analysis (CFA).

\begin{tabular}{|c|c|c|c|c|c|c|c|}
\hline Models & $\chi^{2}$ & $d f$ & $\delta \chi^{2}$ & $\delta d f$ & $T L I$ & CFI & RMSEA \\
\hline Four-Factor Model & 557.4 & 142 & - & - & 0.98 & 0.96 & 0.05 \\
\hline Three-Factor Model & $1,643.7$ & 159 & $1,086.30$ & 17 & 0.75 & 0.84 & 0.17 \\
\hline Two-Factor Model & 689.6 & 184 & 132.2 & 42 & 0.91 & 0.92 & 0.09 \\
\hline One-Factor Model & $2,508.2$ & 194 & $1,950.80$ & 52 & 0.56 & 0.59 & 0.21 \\
\hline
\end{tabular}

$* * p<0.001 ; \chi 2=$ chi-square; $d f=$ degrees of freedom; $\delta \chi 2=$ chi-square difference; $\delta d f=$ degrees of freedom difference; $T L I=$ Tucker-Lewis Index; $C F I=$ Comparative Fit Index; RMSEA= Root Mean Square Error of Approximation

According to $\mathrm{Hu}$ and Bentler's (1999) recommended values for CFA goodness-of-fit indices (TLI and CFI $\geq 0.96$; RMSEA $\leq 0.60)$, and to the significant difference for $\chi^{2}$, the four-factor model fit the data to an acceptable level, $\left[\chi^{2}(142)=557.4, \quad p<.001 ; \quad T L I=0.98 ; \quad C F I=0.96\right.$; $R M S E A=0.05]$, but other models did not fit the data in the present study. Accordingly, these results provide strong evidence that the study's SRL instrument is multi-construct, composed of four constructs (components).

\subsection{Descriptive Statistics and Correlation Analysis}

Table 3 provides descriptive statistics and correlation coefficients among SRL constructs and students' academic performance in English language and mathematics.

Table 3. Descriptive Statistics and Correlation Coefficients among SRL Constructs and Academic Achievements.

\begin{tabular}{|c|c|c|c|c|c|c|}
\hline \multirow{2}{*}{ Construct } & \multicolumn{4}{|c|}{ Correlation Coefficient } & \multirow{2}{*}{ Mean } & \multirow{2}{*}{ Std. Deviation } \\
\hline & 1 & 2 & 3 & 4 & & \\
\hline 1.Goal Setting and Planning & - & & & & 3.11 & 0.674 \\
\hline 2.Keeping Records and Monitoring & $0.732 * *$ & - & & & 3.13 & 0.751 \\
\hline 3.Rehearsal and Memorization & $0.643 * *$ & $0.416 * *$ & - & & 3.64 & 0.627 \\
\hline 4.Seeking Social Assistance & $0.747 * *$ & $0.415 * *$ & $0.401 * *$ & - & 3.28 & 0.665 \\
\hline English Language Scores & $0.564 * *$ & $0.463 * *$ & $0.444 * *$ & $0.431 * *$ & 64 & 22.561 \\
\hline Mathematics Scores & $0.509 * *$ & $0.341 * *$ & $0.353 * *$ & $0.318 * *$ & 67 & 29.873 \\
\hline
\end{tabular}

$* * \mathrm{p} \leq .01$

From Table 3, students' goal setting and planning as an SRL component has the lowest mean value $(\mathrm{M}=3.11$ out of 5), and rehearsal and memorization has the highest mean value $(\mathrm{M}=3.64$ out of 5). Students' average scores in both courses (English language skills and mathematics) arefairly weak given that the minimum pass score is 60 out of 100 points. Furthermore, goal setting and planning as an SRL component has high correlation with other SRL components, ranging from 0.643 to 0.747 . Overall, other correlation coefficients among SRL constructs are moderate with coefficients around 0.30 . Therefore, evidence of convergent validity was indicated by these results where all four constructs were highly intercorrelated.

The findings presented in Table 3 reveal that all correlation coefficients between SRL and English language skills and mathematics scores are significant and positive; therefore, positive relationships between SRL constructs and academic performance in English language skills and mathematics are found. Goal setting and planning had the highest correlation coefficients with academic performance ( $\mathrm{r}=0.564$ and 0.509 for English language and mathematics respectively).

\subsection{Testing Study Hypotheses}

The present study tries to test two main hypotheses regarding the relationship and the predictability between overall SRL and academic achievement of Saudi university students as measured by their scores in the areas of English language skills and mathematics. To accomplish this, a simple regression analysis was performed in which SRL constructs were entered as the predictor variables and English language and mathematics scores were entered as dependent variables to be predicted. Table 4 shows the results of the regression analysis.

Table 4. Regression Coefficient - Model Summary of SRL and English Language Skills and Mathematics.

\begin{tabular}{|c|c|c|c|c|c|c|c|}
\hline Model & $R$ & $R^{2}$ & $R_{a d j}^{2}$ & SE & $F$ & $\bar{\beta}$ & $\bar{t}$ \\
\hline English Language Skills & $0.77^{* *}$ & 0.59 & 0.46 & 2.54 & $12.54 * *$ & 0.56 & $5.43 * *$ \\
\hline Mathematics & $0.62 * *$ & 0.38 & 0.30 & 5.36 & $18.64 *$ & 0.39 & $9.32 * *$ \\
\hline
\end{tabular}

$* * p \leq .01 . * p \leq .05$

The results as outlined in Table 4 indicate that SRL is significantly and positively correlated with scores in the area of English language and mathematics. The correlations between SRL and English language and mathematics are 
found to be 0.77 and 0.62 respectively. With regards to the predictability of English language and mathematics performance by SRL constructs, it is evident from the results that students'English language performanceis predicted by SRL constructs, $F=12.54, p=0.008, R^{2}=0.59$, and students' mathematics performance is also predicted by these constructs, $F=18.64, p=0.014, R^{2}=0.30$.
In the final analysis presented in Table 5, each predicative SRL construct and its contribution to predictability of English language and mathematics performance was employed. It was noted that all SRL constructs significantly predicted students' English language and mathematics performance, and goal setting and planning was the most important predictor, $\beta=.54, p=.03$.

Table 5. Regression Coefficient - Model Summary of SRL constructs and English Language Skills and Mathematics.

\begin{tabular}{|c|c|c|c|c|}
\hline \multirow{2}{*}{ Construct } & \multicolumn{2}{|c|}{ English Language Skills } & \multicolumn{2}{|c|}{ Mathematics } \\
\hline & $\beta$ & $t$ & $\beta$ & $t$ \\
\hline Goal Setting and Planning & 0.65 & $4.42 * *$ & 0.63 & $6.12 * *$ \\
\hline Keeping Records and Monitoring & 0.32 & $2.76^{*}$ & 0.24 & $5.55^{* *}$ \\
\hline Rehearsal and Memorization & 0.28 & $3.31 * *$ & 0.22 & $3.32 * *$ \\
\hline Seeking Social Assistance & 0.35 & $4.09 * *$ & 0.35 & $2.99 *$ \\
\hline
\end{tabular}

$* * p \leq .01 .{ }^{*} p \leq .05$

According to the above findings, the two hypotheses of this current study were accepted on the relationship level and predictability level between SRL and academic achievement in the areas of English language skills and mathematics.

\section{Discussion}

The purpose of the present study was to investigate the relationship the SRL constructs has with academic achievement among Saudi university students. The SRL components were studied using the Arabic version of Purdieet al.'s(1996) instrument, as prepared by Ahmad (2007). Despite the fact that this instrument was originally applied in a Western learning culture, it showed a high degree of validity and reliability in its Arabic version for the present study and limited number of previous studies conducted in Arab learning settings (Ahmad, 2007; Al-jarrah, 2010; Helat and Kojah, 2015). This indicates that this instrument has adequate psychometric properties across cultures in terms of validity and reliability.

Upon further investigation of the relationship between SRL and academic achievement, the results of the present study clearly indicated that SRL was significantly and positively correlated with students' English language and mathematics performance ( $\mathrm{r}=0.77$ and 0.62 respectively). This result has been documented by many studies in foreign and Arabic university settings (Pintrich et al., 1993; Chen, 2002; Ahmad, 2007; Bail et al., 2008; Perels et al., 2009; Aljarrah, 2010; Al-Khatib, 2010; DiBenedetto and Bembenutty, 2011, Yusuf, 2011; Peng, 2012; Ismail and Sharma, 2012; Muhammad and Abu Bakar, 2015). Theexamination of obtained data also indicated that SRL was a significant indicator in the two academic areas of English language skills and mathematics. This finding is consistent with other previous studies (Chen, 2002; Ahmad, 2007; Al-jarrah, 2010; Al-Khatib, 2010, Yusuf, 2011; Peng, 2012; Ismail and Sharma, 2012; Muhammad and Abu Bakar, 2015). These findings can be interpreted through the characteristics of effective SRL studentsduring their learning processes. According to Pintrich and DeGroot (1990), they have the ability to plan, monitor and adjust their learning, and manage their class academic tasks efficiently and effectively withpersistently high task performance, dismissing any distractions. These characteristics in turn enable students to achieve high academic performance. Furthermore, effective SRL students can associate their thoughts and actionswith social and environmental outcomes, because they are internally motivated and independent, and can plan, choose, and innovate or design a social and physical environment to gain knowledge in the best possible manner (Zimmerman, 1986).

A close examination of relationships between SRL constructs and academic achievement indicated that goal setting and planning had a high correlation coefficient with English language and mathematics scores $(r=0.564$ and 0.509 respectively). A possible explanation for this finding might be related to the high positive correlation coefficients between goal setting and planning and other SRL components, which indicated high associations between them. That is to say, seeking social assistance from teachers, family members, or classmates, keeping records and monitoring learning activities and tasks, and rehearsal and memorization may form supportive inputs for the process of goal setting and planning. So, when students set learning goals and develop the needed strategies and plans to achieve these goals, other SRL componentswill lend a helping hand and direction for this process. Therefore, goal setting and planning was the most important predictor of academic achievement $(\beta=.54, p=.03)$. From another point of view, when students with effective goal setting and planning face a learning task, they perform a cycle of cognitive activities by analyzing this task, and setting its requirements in terms of specific objectives and actions, then monitoring their progress toward these objectives (Cromley and Azevedo, 2006). These cognitive activities will enhance students' intrinsic motivation, which in turn has a significant impact on their academic achievement (Zimmerman, 1990).

\section{Conclusion}

The lack of local studies on SRL at Saudiuniversity level 
may result from the limited use of such patterns of learning, where Arab education strategy has indicated in its evaluation of the reality of Arab education that attention has been focused on the modalities and indoctrination on the part of teachers, preservation and recollection on the part of the learners (Arab League Educational, Cultural and Scientific Organization, 2010), which will have a negative impact on the level of education on Arab countries. Therefore, this shortage in studies should be filled to highlight the reality of SRL in the Arab context, and especially in Saudi Arabia. So, the present study should be a key stone along with Ismail and Sharma's study (2012), toset up the foundation for further studies in the field of SRL. In addition, the present study confirms a valid and reliable Arabic version of Purdie et al.'s (1996) instrument that can be used safely by other researchers to conduct studies in the field of SRL in Arab learning contexts, and educators can use and implement this instrument confidently to help their students to measure their SRL level, which can be developed to enhance their academic achievement.

In summary, the major conclusion emerging from the findings of the study is that SRL has an important influence on academic achievement amongst CC students at KSU. This means that SRL facilitates academic achievement in the areas of English language and mathematics. Therefore, educators and education policy makers need to pay close attention to ensure an instructional delivery system and environment that enhance students' acquisition of SRL components, especially in goal setting and planning, since deficiency in these components can lead to weakness in students' academic achievements, especially in English language and mathematics subjects. University academic guidance and counselingdepartments should develop SRL assessment tools to deal with any difficulties in such area.

Along with Western research in the field of SRL, there is a need for future studies in Arab countries to validate other common SRL instruments, scales, and surveys such as the Motivated Strategies for Learning Questionnaire (Pintrich et al., 1993) and the Learning and Study Strategies Inventory (Weinstein et al., 1987), and to provide additional knowledge regarding the methods, programs and strategies that may enhance students' SRL.

The present study has limitations. Datawas obtained from a small sample size that had a relatively homogenous nature (male students from $\mathrm{CC}$ at $\mathrm{KSU}$ ), so larger sample sizesdrawn from different universities and socio-economic backgrounds are needed and desirable in future studies. This will enhance the representativeness and external validity of findings, allowingthemto be generalized. In addition, the influences of some demographic, cultural, and environmental factors on SRL must be investigated in future studies for the Saudi learning context. Furthermore, it is important for future researchers to adopt an integrated and contextualized approach in exploring the predictors of academic achievement at university (Clercq et al., 2012). Finally, concurrent, convergent and predictive validities of the present study instrumentneed further investigation.

\section{Acknowledgements}

This project was supported by King Saud University, Deanship of Scientific Research, Community College Research Unit.

\section{References}

[1] Acar, E., Aktamis. A. (2010). The relationship between selfregulation strategies and prospective elementary school teachers' academic achievement in mathematics teaching course. Procedia Social and Behavioral Sciences, 2, 55395543.

[2] Ahmad, I. I. (2007). Self-regulation of learning and selfmotivation and their relationship with the academic achievement of the students of the College of Education (predictive study). Journal of the College of Education, EinShams University, 31, part 3, 69-135.

[3] Ahmad, S., Hussain, A., \& Ayeem, M. (2012). Relationship of academic self-efficacy to self- regulated learning, school identification, test anxiety, and academic achievement. International Journal of Education, 4, 12-25.

[4] Al-jarrah A. (2010). The relationship between self-regulated learning and academic achievement among sample of Yarmouk university students. The Jordanian Journal of Educational Sciences, 6(4), 333-348.

[5] Al-Khatib, S. A. (2010). Meta-cognitive self-regulated learning and motivational beliefs as predictors of college students' performance. International Journal of Research in Education, (27), 57-72.

[6] Arab League Educational, Cultural and Scientific Organization. (2010). 4th Forum of Arab Parliamentarians for Education (FARPED IV) From 7-9 June 2010 (Lebanon).

[7] Azevedo, R., \& Cromley, R. J. (2004). Does training on selfregulated learning facilitate students' learning with hypermedia?. Journal of Educational Psychology, 96(3), 523535. http://dx.doi.org/10.1037/0022-0663.96.3.523.

[8] Bail, F. T., Zhang, S., \& Tachiyama, G. T. (2008). Effects of a self-regulated learning course on the academic performance and graduation rate of college students in an academic support program. Journal of CollegeReading and Learning, $\quad 39$ (1), 54-73. 10.1080/10790195.2008.10850312.

[9] Bandura, A. (1986). Social foundations of thought and action: A social cognitive theory. Englewood Cliffs, N.J: PrenticeHall.

[10] Beishuizen, J., \& Steffens, K. (2011). A conceptual framework for research on self-regulated learning. In R. Carneiro, P. Lefrere, K. Steffens, K. \& J. Underwood (Eds.), Self-regulated Learning in Technology Enhanced Learning Environments: A European Perspective. Rotterdam: Sense Publishers.

[11] Bembenutty, H. (2006). Self-regulation of learning. Academic Exchange Quarterly, 10 (4), 221- 248.

[12] Butler, D. (2002). Individualizing instruction in self-regulated learning. Theory into Practice, 41(2), 8192.doi:10.1207/s15430421 tip4102_4. 
[13] Butler, D., \& Winne, P. (1995). Feedback and self-regulated learning: A theoretical synthesis. Review of Educational Research, 651(3), 245-281. doi:10.3102/00346543065003245.

[14] Chen, C. S. (2002). Self-regulated learning strategies and achievement in an introduction to information systems course. Information Technology, Learning and Performance Journal, 20(1), 11-23.

[15] Clercq, M., Galand, B., Dupont, S., \& Frenay, M. (2012). Achievement among first-year university students: an integrated and contextualised approach. European Journal of Psychology of Education, 28(3), 641-662. doi:10.1007/s10212-012-0133-6.

[16] Corsi, G. (2010). Self-regulated learning: studying the effects of a nontraditional instructional method in the high school science classroom. National Science Teachers Association, 77 (7), 58-62.

[17] Dent, A. L., \& Koenka, A. C. (2015). The relation between self-regulated learning and academic achievement across childhood and adolescence: A meta-analysis. Educational Psychology Review, 27(3),1-50. doi:10.1007/s10648-0159320-8

[18] DiBenedetto, M. K., \& Bembenutty, H. (2011). Within the pipeline: self-regulated learning and academic achievement among college students in Science courses. A paper presented during the American Educational Research Association Annual Meeting, April 10, 2011, New Orleans, Louisiana.

[19] Effeney, G., Carroll, A., \& Bahr, N. (2013). Self-regulated learning:Key strategies and their sources in a sample of adolescent males. Australian Journal of Educational \& Developmental Psychology, 13, 58-74.

[20] Fabriz, S., Dignath-van Ewijk, C., Poarch, G., \& Büttner, G. (2014). Fostering self-monitoring of university students by means of a standardized learning journal - a longitudinal study with process analyses. European Journal of Psychology of Education, 29(2),239-255. doi:10.1007/s10212-013-0196-z.

[21] Fadlelmula, F. K., Cakiroglu, E., \& Sungur, S. (2015). Developing a structural model on the relationship among motivational beliefs, self-regulated learning strategies, and achievement in mathematics. International Journal of Science and Mathematics Education, 13(6), 1355-1375. doi:10.1007/s10763-013-9499-4

[22] Hassan, F. H. (1995). Strategies of self-regulated learning and their relationship with academic achievement and level of intelligence of second graders of preparatory education. Journal of the College of Education in Zagazig, 22, 159-191.

[23] Helat, M. K., \& Kojah, A. M. (2015). Self-regulating learning: Comparative study between distinguished and nondistinguished students. 2nd International Conference for Distinguished and Talented Students, United Arab Emirate University, 19-21 May 2015.

[24] Hong, E.; Peng, Y.; \& Rowell, R. (2009). Homework selfregulation: Grade, gender, and achievement-level differences. Learning and Individual Differences, 19, 269-276.

[25] Hu, L. T., and Bentler, P. M. (1999). Cutoff criteria for fit indexes in covariance structure analysis: Conventional criteria versus new alternatives. Structural Equation Modeling, 6 (1), $1-55$.
[26] Ibrahim, L. A. (1996). Components of Self-regulated learning and their relationship with self-esteem, achievement and facing the failure in academic achievement. Journal of Educational Research at Qatar University, 10, 199-236.

[27] Ismail, N. M., \& Sharma, A. (2012). Goal orientation and selfregulated learning strategies as predictors of EFL students' GPA. Journal Of Educational Review, 5(1), 111-125.

[28] Judd, J. (2005). The relationship between self-regulatory learning strategies and the academic achievement of high school chemistry students. Unpublished thesis inthe University of Hawaii, USA. http://scholarspace.manoa.hawaii.edu/bitstream/handle/10125/ 10439/uhm_med_530_r.pdf. Accessed 25 January 2016.

[29] Kolovelonis, A., Goudas, M., Dermitzaki, I., \& Kitsantas, A. (2012). Self-regulated learning and performance calibration among elementary physical education students. European Journal of Psychology of Education, 28(3), 685-701. doi $=10.1007 / \mathrm{s} 10212-012-0135-4$.

[30] Mace, F. C., Belfiore, P. J., \& Hutchinson, J. M. (2001). Operant theory and research on self-regulation. In B. J. Zimmerman \& D. H. Schunk (Eds.), Self-regulated learning and academic achievement: Theoretical perspectives (2nd ed., pp. 39-65). Mahwah, NJ: Erlbaum.

[31] Farajollahi, M., \& Moenikia, M. (2010). The study of relation between students support services and distance students' academic achievement. Procedia Social and Behavioral Sciences, 2, 4451-4456. doi:10.1016/j.sbspro.2010.03.710.

[32] Muhammad, A. S., \& Abu Bakar, N. (2015). Relationship of self-regulated learning and academic achievement among universiti sultan zainalabidin (UNISZA) undergraduate students. International Conference on Empowering Islamic Civilization in the 21st Century, 6-7 September 2015 Universiti Sultan ZainalAbidin, Malaysia.

[33] Ocak, G., \& Yamac, A. (2013). Examination of the relationships between fifth graders' self-regulated learning strategies, motivational beliefs, attitudes, and Achievement. Educational Sciences: Theory \& Practice, 13, 380-387.

[34] Organization for Economic Cooperation and Development. (2003). The PISA 2003 Technical Report. https://www.oecd.org/edu/school/programmeforinternationalst udentassessmentpisa/35188570.pdf. Accessed 20 March 2016.

[35] Peng, C. (2012). Self- regulated learning behavior of college students of science and their academic achievement. Physics procedia, 33, 1446-1450.

[36] Perels, F., Dignath, C., \& Schmitz, B. (2009). Is it possible to improve mathematical achievement by means of selfregulation strategies? Evaluation of an intervention in regular math classes. European Journal of Psychology of Education, 24(1): 17. doi:10.1007/BF03173472.

[37] Perry, N, Phillips, L, \& Hutchinson, L. (2006). Mentoring student teachers to support self-regulated learning. The Elementary School Journal, 106(3), 237-254. doi:10.1086/501485.

[38] Pintrich, P. R. (2000). The role of goal orientation in selfregulated learning. In M. Boekaerts, P. R. Pintrich, \& M. Zeidner (Eds.), Handbook of self-regulation (pp. 451-502). San Diego: Academic Press. 
[39] Pintrich, P. R. (2004). A conceptual framework for assessing motivation and self-regulated learning in college students. Educational Psychology Review, 16(4), 385-407. doi:10.1007/s10648-004-0006-x.

[40] Pintrich, P. R., \& DeGroot, E. V. (1990). Motivational and self-regulated components of classroom academic performance. Journal of Educational Psychology, 82(1), 3340 .

[41] Pintrich, P. R., Smith, D. A. F., Garcia, T., \& McKeachie, W. (1993). Reliability and predictive validity of the Motivated Strategies for Learning Questionnaire (MSLQ). Educational and Psychological Measurement, 53(3), 801-813. doi:10.1177/0013164493053003024.

[42] Purdie, N., Hattie, J., \& Douglas, G. (1996). Student conceptions of learning and their use of self-regulated learning strategies: A cross-cultural comparison. Journal of Educational Psychology, 88(1), 87-100. doi:10.1037/00220663.88.1.87.

[43] Rakes, G. C., \& Dunn, K. E. (2010). The impact of online graduate students' motivation and self-regulation on academic procrastination. Journal of Interactive Online Learning, 9(1), 78-93.

[44] Rosário, P., Núñez, J., Valle, A., González-Pienda, J., \& Lourenço, A. (2013). Grade level, study time, and grade retention and their effects on motivation, self-regulated learning strategies, and mathematics achievement: A structural equation model. European Journal of Psychology ofEducation. 28(4):1311-1331. doi:10.1007/s10212-012-01679.

[45] Sadia O., \& Uyar, M. (2013). The relationship between selfefficacy, self-regulated learning strategies and achievement: A path model. Journal of Baltic Science Education, 12, 21-33.

[46] Schunk, D. H. (2005). Self-regulated learning: The educational legacy of Paul R. Pintrich. Educational Psychologist, 40(2), 85-94. doi:10.1207/s15326985ep4002_3.

[47] Schunk, D. H. (2011). Learning Theories: An Educational Perspective. Boston, MA: Pearson.

[48] Schunk, D. H., \& Zimmerman, B. J. (2008). Motivation and self-regulated learning: Theory, research and applications. New York: LEA.

[49] Sui-Chu, H. (2004). Self-regulated learning and academic achievement of Hong Kong secondary school students. Education Journal, 32 (2), 87-107.
[50] Tanriseven, I., \& Dilmac, B. (2013). Predictive relationships between secondary school students' human values, motivational beliefs, and self- regulated learning strategies. Educational Sciences: Theory \& Practice, 13, 29-36.

[51] Vygotsky, L. S. (1978). Interaction between learning and development. In M. Cole, V. John-Steiner, S. Scribner, \& E. Souberman (Eds.), Mind in society: The development of higher psychological processes (pp. 79-91). Cambridge, MA: Harvard University Press.

[52] Yusuf, M. (2011). The impact of self-efficacy, achievement motivation, and self-regulated learning strategies on students' academic achievement. Procedia Social and Behavioral Sciences, 15, 2623-2626.

[53] Weinstein, C. E., Palmer, D. R., \& Schulte, A. C. (1987). LASSI-Learning and study strategies inventory. Clearwater, FL: H \& H Publishing.

[54] Zimmerman, B. (1986). Becoming a self-regulated learner: which are the key subprocesses?. Contemporary Educational Psychology, 11(4), 307-313. doi:10.1016/0361476X(86)90027-5.

[55] Zimmerman, B. (1990). Self- regulated learning and academic achievement: An overview. Educational psychologist, 25(1), 3- 17. doi:10.1207/s15326985ep2501 2.

[56] Zimmerman, B. (1995). Self- regulation involves more than metacognitions: A social cognitive perspective. Educational $\begin{array}{lllll}\text { psychologist, } & 30 & \text { (4), } & 217- & \end{array}$ doi:10.1207/s15326985ep3004 8.

[57] Zimmerman, B. J. (2002). Becoming a self-regulated learner: An overview. Theory into Practice, 41(2), 64-72. doi:10.1207/s15430421tip4102_2.

[58] Zimmerman, B. J. (2008). Investigating self-regulation and motivation: Historical background, methodological developments, and future prospects. AmericanEducational Research Journal, 45(1), 166-183. doi:10.3102/0002831207312909.

[59] Zimmerman, B. J., \& Martinez-Pons, M. (1986). Development of a structured interview for assessing student use of self-regulated learning strategies. AmericanEducational $\begin{array}{llll}\text { Research Journal, } & \text { 23(4), 614-28. }\end{array}$ doi:10.3102/00028312023004614.

[60] Zimmerman, B. J., \& Schunk, D. H. (2011). Self-regulated learning and performance. In B. J. Zimmerman and D. H. Schunk (Eds.), Handbook of self-regulation of learning and performance (pp. 1-12). New York: Routledge. 